\title{
UNUSUAL CASE OF AN ENORMOUS DERMOID CYST IN A 16-YEAR-OLD GIRL
}

\author{
Kovachev E. ${ }^{1,2}$, K. Aleksandrov ${ }^{2}$, M. Veseli ${ }^{1}$ \\ ${ }^{I}$ Department of Obstetrics and Gynecology, Medical University, Varna \\ ${ }^{2}$ Medical Centre of Assisted Reproduction "Varna", LTD
}

Reviewed by: prof. I. Kozovski

\begin{abstract}
We present the case of a 16-year old girl with a large dermoid cyst from right ovary. Ultrasound examination and MRI were performed, which visualized a huge multilocular ovarian tumour formation, situated in pelvic and whole abdominal cavity. We performed an exploratory laparotomy, oophorocystectomy and, in our case, the organ preserving operation was completely sufficient. The histological examinations reported mature cystic teratomas (Dermoids) without morphological data for malignant transformation.
\end{abstract}

Key words: mature teratomas, dermoid cysts, cystectomy

\section{INTRODUCTION}

More than $80 \%$ of benign cystic teratomas occur during the reproductive years. Dermoids, or mature cystic teratomas, are benign germ cell tumors of the ovary and are the most common neoplastic cysts found in adolescents (4). They arise from totipotential cells in the ovary and can give rise to tissues arising from the ectoderm, mesoderm, and endoderm, including hair, bone, primitive teeth, cartilage, sebaceous material, and nerve tissue (3).

While most mature teratomas contain cells from all germ cell layers, a subset of monodermal teratomas exists. Those tumors composed mostly or entirely of thyroid tissue are called struma ovarii. These tumors account for only $3 \%$ of all teratomas, and only $5 \%$ of these will produce symptoms of thyrotoxicosis.

Dermoids can be present with dull abdominal pain but are frequently asymptomatic and often found by pelvic examination or incidental imaging. The risk of torsion with dermoid cysts is approximately $15 \%$. Malignant transformation occurs in less than $2 \%$ of dermoid cysts in women of all ages; most cases occur in women older than 40 years of age (2). They have a characteristic ultrasound appearance with fat fluid levels, diffuse or focal areas of increased echogenicity with acoustical shadowing, often thought to be hair fibers and sebaceous material within the cyst and may contain a mural hyperechogenic nodule (fig. 2). Ultrasound, CT or MRI is almost pathognomonic for a dermoid cyst and frequently is described

\footnotetext{
Address for correspondence:

E. Kovachev, SBAGAL - Varna, Dept. of Obstetrics and Gynecology; Medical Centre of Assisted Reproduction "Varna" Ltd,

150, Tsar Osvoboditel Blvd., 9000 Varna - Bulgaria

e-mail: kovachev_md@abv.bg
}

as anterior in location (7), (fig. 3). In adolescents, dermoid cysts are bilateral in approximately $10 \%$ of patients, so careful evaluation of both ovaries is indicated by imaging and at the time of surgery $(4,1)$.

Dermoid cysts rarely can rupture spontaneously, but chemical peritonitis, foreign body reaction, and dense adhesions can be sequelae (6).

Ovarian cystectomy is almost always possible, even if it appears that only a small amount of ovarian tissue remains (1).

Studies have detailed several advantages to the laparoscopic approach of removal of dermoids, including less postoperative pain and blood loss, shorter hospital stay (5). If intraoperative spillage occurs, the possibility of chemical peritonitis or excess adhesion formation leads to the recommendation that copious saline irrigation should be used until the lavage is clear.

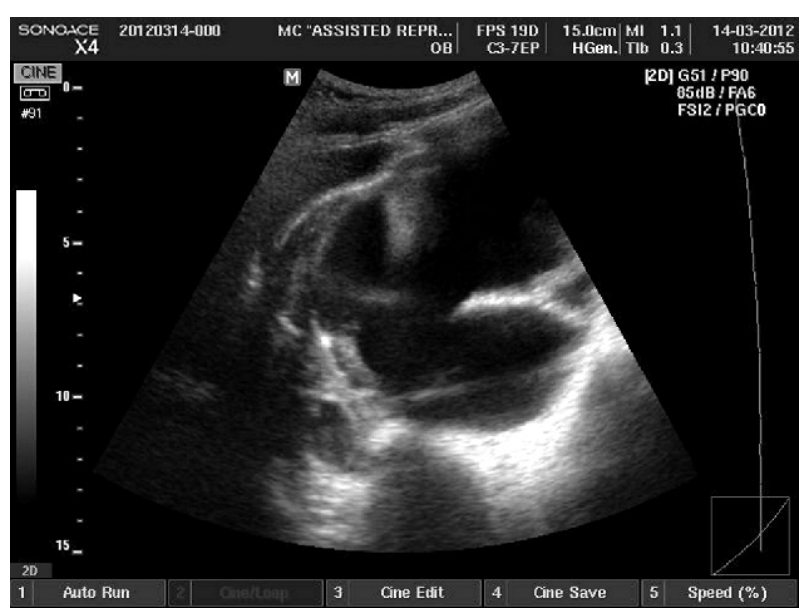

Figure 1. Ultrasound view of a mature teratoma with long echogenic lines (our case). 


\section{Case presentation}

A 16-year-old girl was hospitalized in the gynecological department with abdominal discomfort and increasing abdominal circumference. Pelvic examination revealed the presence of a large tumor mass, measuring over $20 \mathrm{~cm}$ in diameter. The ultrasound examination and magnetic resonance (MRI), demonstrated a huge multilocular ovarian tumor formation from right ovary, situated in the pelvis and upper abdomen with high signal intensity of fat on T1-weighted images and heterogeneous texture without ascites (fig. 1, fig. 2, fig. 3).

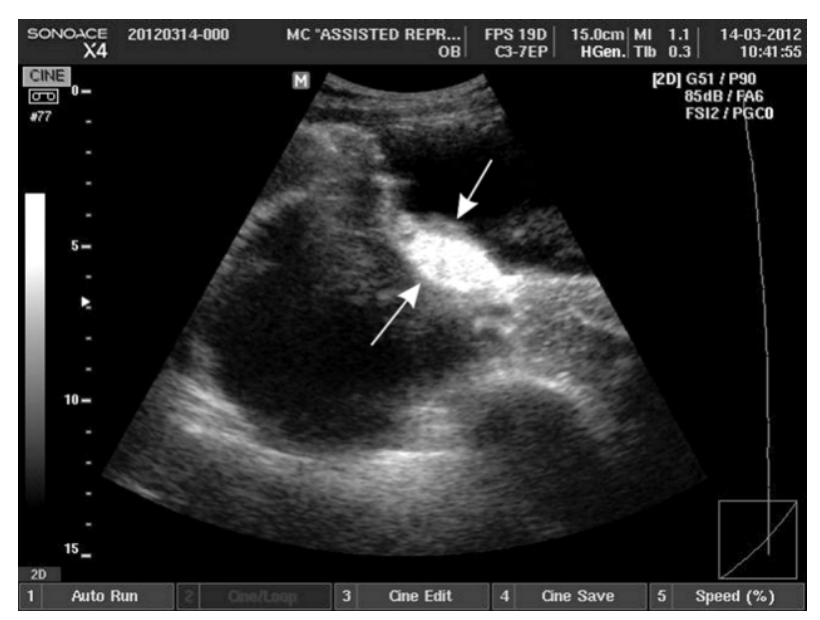

Figure 2. Ultrasound image of a dermoid with mural hyperechogenic nodule (our case).

Labarotory test were normal, espessially CA 125 - 17,08 $\mathrm{U} / \mathrm{ml}$. We performed an exploratory laparotomy with lower longitudinal incision. An enormous tumor was found, originating from the right ovary, with intact capsule which was clamped, ligated under direct vision and resected (oophorcystectomy). The uterus and the left ovary were normal and the tumor was sent for frozen section. The result should a benign mature cystic teratoma (fig. 4).

The postoperative period was uneventiful and the patient was discharged from the hospital six days after the surgery.

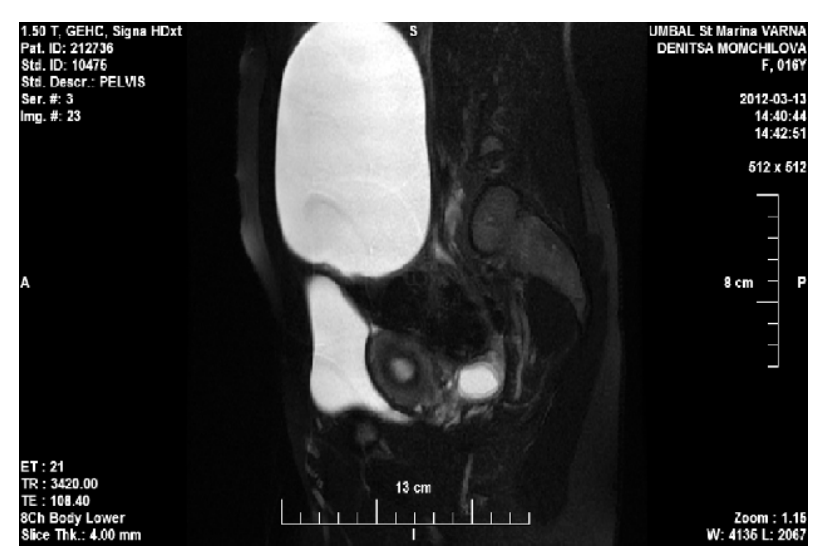

Figure 3. MRI, visualizing a huge ovarian tumour from right ovary, normal uterus size (our case).

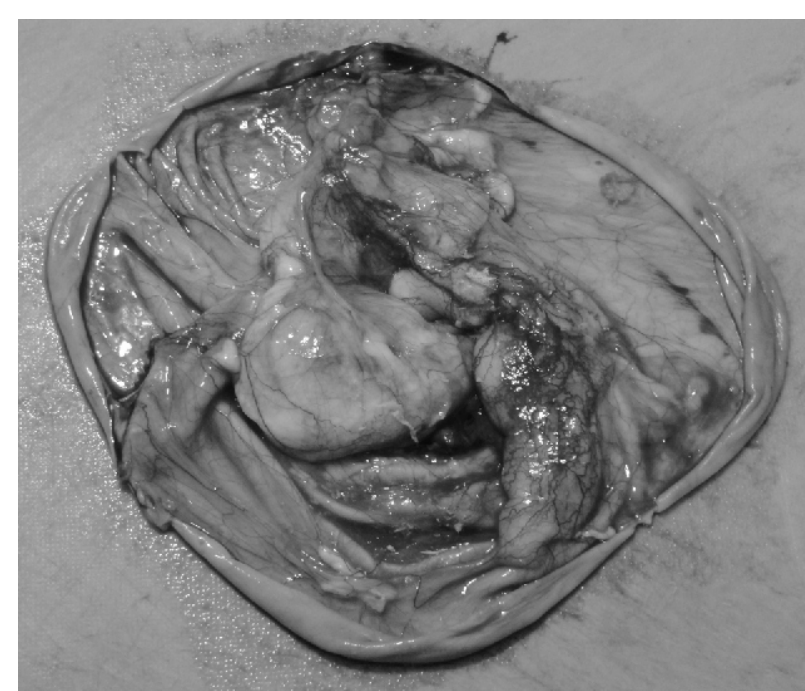

Figure 4. View of a large dermoid (our case).

The final histopathological report revealed a benign mature cystic teratoma with hemorrhagic necroses.

\section{DISCUSSION}

Transvaginal ultrasound is known to be very accurate in the diagnosis of dermoid cysts, with hair and sebum, rather than calcium, creating highly reflective irregular solid components within fluid-containing masses $(6,7)$.

Hair follicles, skin glands, muscle, and other tissues are found within the wall. There is usually a raised protuberance projecting into the cyst cavity known as the Rokitansky nodule (dermoid plug), which is hyperechogenic with shadowing due to adipose tissue, hair, or calcifications $(2,7)$. The most characteristic ultrasound features of a mature cystic teratoma are the presence of a white ball (corresponding to hair and sebum) and long echogenic lines and prominent echogenic dots in cyst fluid (fig. 1). Shadowing often makes it difficult or impossible to correctly measure the size of dermoids.

Owing to the slow growth rate of dermoids, with an average rate of 1,8 $\mathrm{mm}$ each year, some investigators advise nonsurgical management of smaller $(<6 \mathrm{~cm})$ tumors. Mature cystic teratomas requiring removal can be treated with simple cystectomy.

\section{CONCLUSION}

While a bimanual examination typically can identify the presence of larger ovarian tumor, ultrasonography and MRI is the standard tool to evaluate the ovarian tumor. In this case the large tumour size and the fast growth of this mature cystic teratoma is very untypical in a young 16-year-old patient. 
Our patient had not visited routine gynecological and ultrasound examinations previously and the result was the enormous tumor size.

Mature cystic teratomas, requiring removal, can be treated with simple cystectomy or oophorcystectomy.

In our rare case the organ preserving operation was a completely sufficient surgical staging procedure.

\section{REFERENCES}

1. Berek J. Novak' gynecology. 13 ed, Lippincott Williams \& Wilkins, 2002; 377:383.

2. Callen, Peter W. Ultrasonography in Obstetrics and Gynecology. Fift Edition, Saunders Elsevier, 2008; 972-974.
3. DeCherrney A, Nathan L. Current Obstetric \& Gynecologic Diagnosis \& Treatment. Ninth Edition, The McGraw-Hill, 2003, 713-714.

4. Diamond MP, Baxter JW, Peerman GCJ, et al. Occurrence of ovarian masses in childhood and adolescence: a community-wide evaluation. Obstet Gynecol 1988; 71:858-860.

5. Mecke H, Savvas V. Laparoscopic surgery of dermoid cysts - intraoperative spillage and complications. Eur J Obstet Gynecol Reprod Biol 2001; 96:80-84.

6. Salhan, S. Textbook of Gynecology. First Edition, Jaypee Brothers Medical Publishers, 2011, 344-345.

7. Yamashita Y, Torashima M, Hatanaka Y, et al. Adnexal masses: accuracy of characterization with transvaginal US and precontrast and postcontrast MR imaging. Radiology 1995; 194:557-565. 